\section{Integrative Medicine \\ International}

\title{
The Impact of School Environment on Children's Respiratory Health
}

\author{
Peter Fsadni ${ }^{a} \quad$ Frank Bezzina $^{\mathrm{b}} \quad$ Claudia Fsadni ${ }^{a} \quad$ Noel Aquilina ${ }^{c}$ \\ Stephen Montefort ${ }^{a}$ \\ a Department of Medicine, Faculty of Medicine and Surgery, ${ }^{b}$ Faculty of Economics, \\ Management and Accountancy, and ${ }^{C}$ Faculty of Science, University of Malta, Msida, Malta
}

\section{Key Words}

International Study of Asthma and Allergies in Childhood - Wheezing · Rhinitis · Indoor air . School

\begin{abstract}
Background/Aims: School indoor air quality is important because children spend most of their time outside home within the school environment. This study aimed to investigate the school environment and its impact on the respiratory health of the children. Methods: A total of 191 pupils in the 9- to 11-year age group were selected from 5 primary state schools. Validated school and health questionnaires, spirometry, acoustic rhinometry, nasal lavage, urine for environmental tobacco smoke biomarkers and traffic counts were used. Results: Cumulative (32.98\%) and current wheezing (17.8\%) were in keeping with the International Study of Asthma and Allergies in Childhood Malta data. Southern schools had the highest prevalence of current wheezers (OR 3.77; $p=0.012$ ), rhinoconjunctivitis (OR 3.59; $p=0.003$ ) and nasal eosinophilic cationic protein levels $(p<0.001)$. Small openable window areas increased rhinitic symptoms (OR 3.14; $p=0.016$ ). Classes facing roads had increased current wheezers (OR 2.27; $p=0.03)$ and exhaled carbon monoxide (eCO) levels $(p<0.001)$. Current wheezing was significantly associated with the number of light and heavy vehicles passing near the school $(p<0.001)$. The presence of smokers at home was significantly associated with urinary cotinine and $3 \mathrm{HC}(p<0.001)$. Proximity to power plants increased the current wheezers (OR 5.89; $p=0.001)$ who had impaired spirometry $(p=0.003)$. Asthma symptoms (OR $5.25 ; p=0.001)$ and elevated eCO levels $(p<0.001)$ were associated with fuel storage facilities near schools. The accumulation of dust on flat surfaces within classrooms was related to wheezing (OR 5.23; $\mathrm{p}=0.001)$. Conclusions: The school environment had a direct impact on the respiratory health of children, with several factors having a direct impact on the children's health.
\end{abstract}


Integrative
Medicine

International

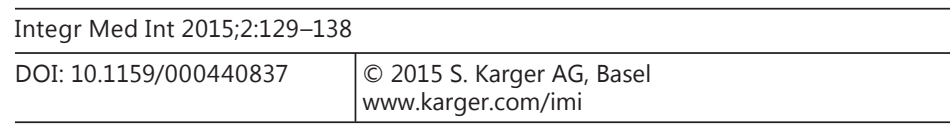

Fsadni et al.: The Impact of School Environment on Children's Respiratory Health

\section{Introduction}

The International Study of Asthma and Allergies in Childhood (ISAAC) Malta showed an increase in prevalence of wheezing among 5- to 8-year-olds between phase 1 (1994) and phase 3 (2001) [1], with most regions of the Maltese islands reporting an increase in wheezing [2]. Due to the small size of Malta, the climate is similar in all the regions studied, thus exposing residents to similar viral infections [3], perennial and seasonal allergens, which may influence atopic disease in childhood. Malta has dust deposition levels 5 times the European average [4]. Traffic may also influence the geographical variations of asthma, since Malta has the fifth highest number of vehicles per capita in the world [5]. Diesel has been found to increase IL-10 in the airways of exposed individuals [6], thus predisposing them to developing asthma. Genetic components and environmental factors must influence the geographical distribution of wheezing in the Maltese islands.

Studies have highlighted the role of dust mites, cockroaches, cats, dogs and fungi as contributors to the development or progression of atopic disease [7]. A negative correlation exists between acute asthma admissions in Malta and mean monthly ambient temperatures, which might suggest that temperature is a proxy for the time spent indoors [8]. School environments with high levels of cat, dog, cockroach, mould and dust allergens have an increased incidence of asthma diagnosis among the pupils [9-11] confirmed by an increase in eosinophil peroxidase and myeloperoxidase (MPO) in the sputum of exposed children [12].

To date, there is no data regarding the impact of school indoor air quality on the children's health in island nations such as Malta. Extrapolation of data obtained in studies carried out in Europe or the US is impossible due to the unique environmental and geographical characteristics.

\section{Materials and Methods}

\section{Data Collection}

Five primary state schools were selected randomly from 5 geographical clusters of schools designated north, south, central, east and west. Three classrooms within each school were selected among the 9- to 11-year age group with all students being asked to participate. The classrooms were randomly selected by a ballot system so as to eliminate potential bias. Primary state schools in Malta are coeducational. The data collection was carried out between October 2011 and February 2012.

\section{Ethical Approval and Consent}

This study was approved by the University of Malta Research Ethics Committee and the Education Department Research Directorate. Both students and their parents were given written information sheets about the study, and a meeting for all students and parents was held at each school. Parents were asked to sign a consent form.

\section{Questionnaires}

Standardized health questionnaires based on the ISAAC [13] were answered by the children's parents. All 5 school buildings were analyzed using checklists and questionnaires so as to obtain a detailed architectural profile of each school and classroom [14]. School cleaning and maintenance routines were also assessed. 
Table 1. Student demographics in all 5 schools

\begin{tabular}{llllrrrr}
\hline \multirow{2}{*}{ Parameter } & School & Number of pupils & Mean & Median & SD & Max & Min \\
\hline \multirow{2}{*}{ Weight, kg } & S1 & 44 & 38.53 & 35 & 14.09 & 85 & 21 \\
& S2 & 34 & 37.06 & 35 & 9.35 & 64 & 24 \\
& S3 & 42 & 40.43 & 34 & 15.11 & 76 & 19 \\
& S4 & 36 & 36.42 & 33.5 & 11.72 & 81 & 24 \\
& S5 & 35 & 40 & 35 & 12.8 & 76 & 25 \\
\hline Height, cm & S1 & 44 & 138.38 & 136 & 8.37 & 156 & 126 \\
& S2 & 34 & 139.53 & 138 & 6.46 & 154 & 123 \\
& S3 & 42 & 142.14 & 142 & 10.51 & 161 & 116 \\
& S4 & 36 & 135.28 & 135 & 5.31 & 146 & 126 \\
& S5 & 35 & $3,231.13$ & 3,300 & 844.11 & 6,200 & 1,587 \\
& S1 & 44 & $3,543.8$ & 3,480 & 934.7 & 7,300 & 1,590 \\
& S2 & 34 & $3,411.1$ & 3,350 & 610.2 & 4,800 & 2,240 \\
& S3 & 42 & $3,142.19$ & 3,250 & 621.46 & 3,900 & 1,200 \\
& S4 & 36 & $3,254.23$ & 3,165 & 574.45 & 4,350 & 1,850 \\
\hline
\end{tabular}

\section{Clinical Tests}

Clinical tests were performed on all pupils who consented within the selected classrooms. Tests included spirometry (microQuark COSMED) [15], exhaled nitric oxide (NIOX $\mathrm{MINO}^{\circledR}$ ) [16], exhaled carbon monoxide (eCO; piCO+ ${ }^{\mathrm{TM}} \mathrm{CO}$ ) [17] and acoustic rhinometry of the nasal cavity (A1 Acoustic Rhinometer by GM Instruments) [18]. Nasal lavage in randomly selected students was performed after acoustic rhinometry and analyzed for MPO, eosinophilic cationic protein (ECP), lysozyme and albumin. ECP and MPO were determined by double antibody radioimmunoassay $[19,20]$. Lysozyme was analyzed using radioimmunoassay [21], and rate nephelometry on an Array protein system was utilized for albumin [22]. Students were asked to provide a morning urine sample for cotinine and trans-3-hydroxycotinine (3HC), which are markers of environmental tobacco smoke (ETS) exposure. A manual traffic count was performed in the roads adjacent to each of the 5 individual schools.

\section{Statistical Analysis}

Questionnaires were analyzed using IBM SPSS Statistics version 21 (Chicago, Ill., USA). The $\chi^{2}$ and Fisher exact tests were utilized to examine the association between categorical variables for ordinal data, and the Mann-Whitney $U$ test was used to determine whether a significant difference existed between 2 independent groups.

For statistical significance, a p value cutoff point of 0.05 was adopted. Regression analysis was used to eliminate any possible confounding factors.

\section{Results}

One hundred and ninety-one (80.59\%) students consented to taking part in the study, with $51.16 \%$ of the pupils being females and $48.84 \%$ being males (table 1 ). Of all the pupils, $32.98 \%$ had wheezing 'ever', while $17.8 \%$ had current wheezing in the previous 12 months. Allergic rhinitis 'ever' was present in $34 \%$ of the children, while $29.84 \%$ complained of rhinitic symptoms in the previous 12 months (table 2). Cumulative rhinitic symptoms peaked during May (36.92\%; $p \leq 0.001$ ) and November (40\%; $<<0.001)$, with $43 \%$ of the pupils complaining that these symptoms interfere with daily activities. 


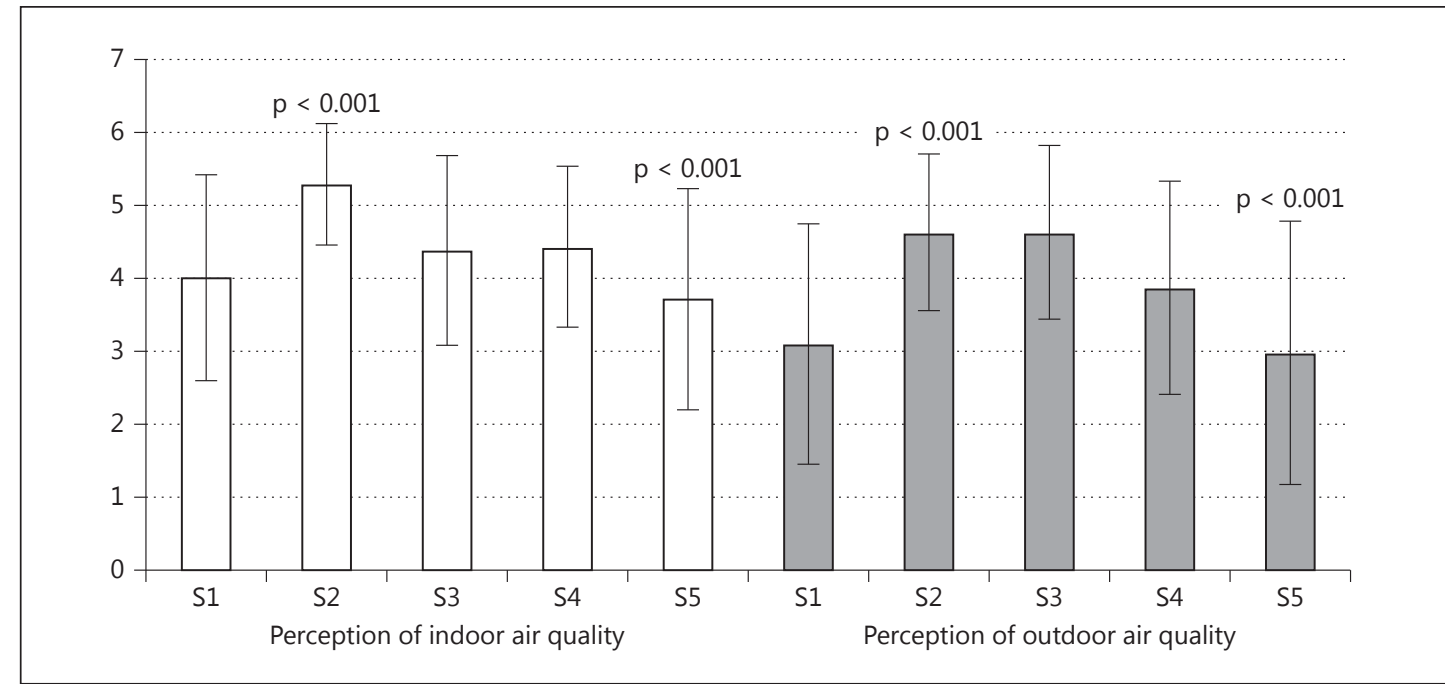

Fig. 1. Air quality perception scores in each individual school. S1 = School 1 (central); S2 = school 2 (east/ coast); S3 = school 3 (west/rural); S4 = school 4 (south); S5 = school 5 (center/south).

Table 2. Prevalence (\%) of wheezing and rhinitis in all 5 schools

\begin{tabular}{llllll}
\hline Symptom & \multicolumn{2}{l}{ School } & & & \\
\cline { 2 - 6 } & S1 & S2 & S3 & S4 & S5 \\
\hline Wheezing ever & 36.60 & 20.58 & 28.57 & 36.11 & 42.86 \\
Current wheezing & 20.45 & 11.76 & 11.91 & 25.00 & 20.00 \\
Doctor diagnosed asthma & 18.18 & 11.77 & 9.52 & 16.67 & 28.57 \\
Current rhinitis & 13.63 & 34.24 & 26.19 & 39.11 & 40.00 \\
\hline
\end{tabular}

S1 = School 1 (central); S2 = school 2 (east/coast); S3 = school 3 (west/rural); S4 = school 4 (south); S5 = school 5 (center/south).

Pupils graded indoor and outdoor air quality of the schools on a scale from 1 to 6, with 1 being very poor and 6 being excellent (fig. 1). The mean scores were 4.27 (SD 1.67) for indoor air quality and 3.71 (SD 1.87) for outdoor air quality. Southern located schools scored lowest for both indoor (3.71, SD 1.51, p < 0.001) and outdoor air quality $(2.97$, SD 1.78, $\mathrm{p}=$ 0.003 ) when compared to the other schools.

ETS exposure within homes was identified as an independent risk factor for wheezing in this cohort of students who were more likely to complain of exercise-induced wheezing in the previous 12 months (OR 2.54, CI 2.32-8.7, p = 0.032).

Urine samples were analyzed for cotinine and $3 \mathrm{HC}$ as surrogate markers for ETS exposure. Students in schools 1 (Qormi) and 4 (B'Bugia) had the highest mean levels of both metabolites $(\mathrm{p}<0.001)$.

There was a significant positive correlation between the two metabolites within the whole cohort $(\mathrm{r}=0.87 ; \mathrm{p}<0.001)$. Both urinary cotinine and 3HC levels were significantly associated with the presence of smokers within the domestic environment $(p<0.001)$; however, there was no correlation with eCO. 
Fig. 2. Forest plot showing an association between symptoms and the southern location of schools. ADLs = Activities of daily living.

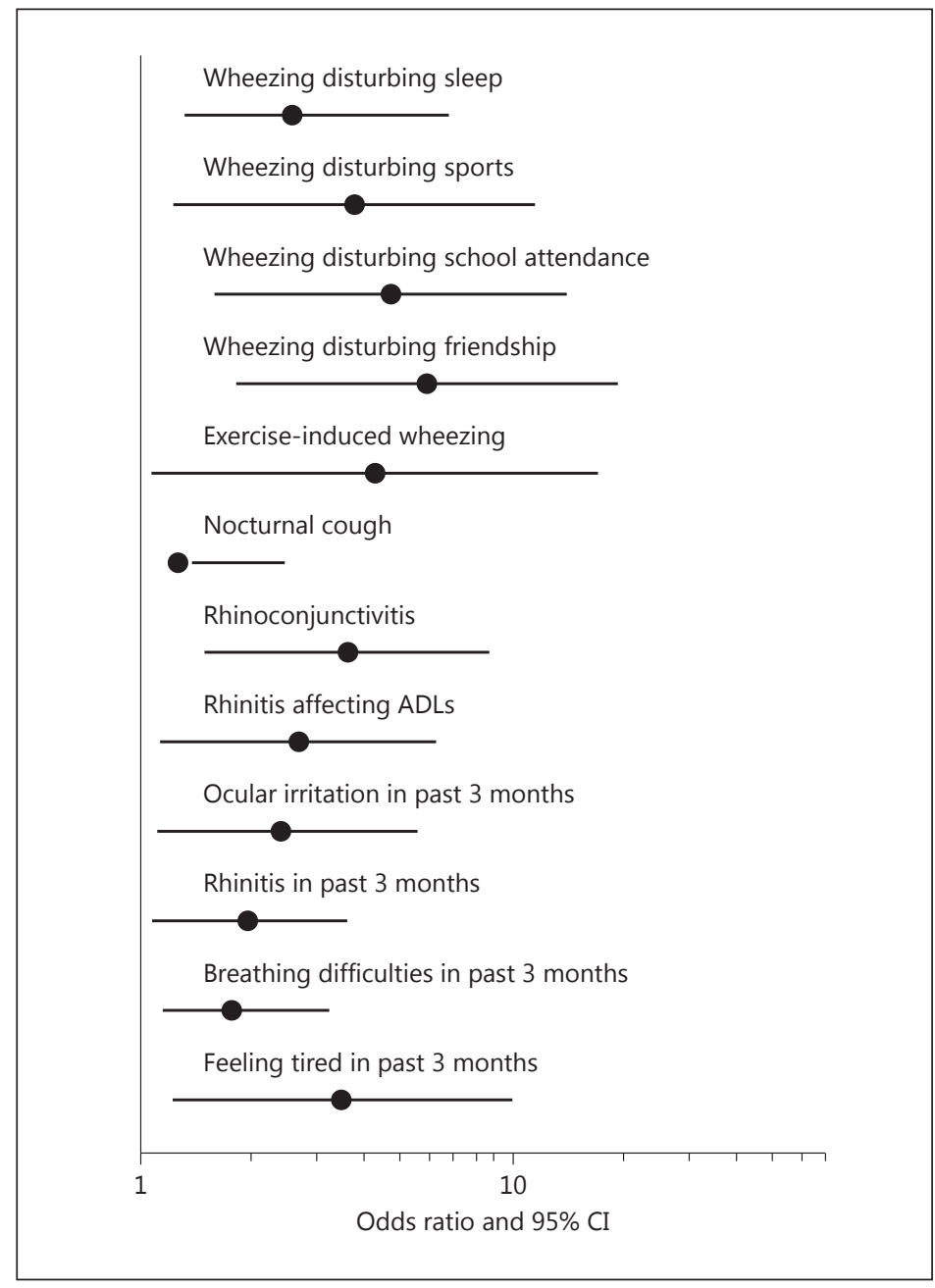

\section{School Environment and Health}

School Location

Southern located schools (fig. 2) were associated with an increase in current wheezers (OR 3.77, CI 1.23-11.53, p = 0.012), exercise-induced wheezing (OR 4.27, CI 1.07-17.06, p < 0.001 ) and nocturnal dry cough (OR 1.26, CI 1.38-2.43, p = 0.019). There was an increase in current allergic rhinoconjunctivitis (OR 3.59, CI 1.49-8.64, $\mathrm{p}=0.003$ ) and low minimal crosssectional areas of both nostrils $(\mathrm{p}=0.015)$. A total of 942 light cars and 87 heavy goods vehicles passed by the schools during the sampling period, with current wheezing being significantly associated with both light and heavy vehicle traffic $(\mathrm{p}<0.001)$. Children in classrooms facing a street complained of current wheezing (OR 2.27, CI 1.07-4.82, p = 0.03) and had raised eCO levels ( $p<0.001)$, narrow nasal cross-sectional areas $(\mathrm{p}<0.001)$ and volumes $(\mathrm{p}=0.014)$, and increased nasal lysozyme levels ( $\mathrm{p}=0.008$; fig. 3 ). Lung function tests were significantly better $(p<0.001)$ in children attending rural schools when compared to urban schools.

Schools situated close to power plants and fuel storage facilities had an increased prevalence of current wheezing (OR 5.89, CI 1.82-19.08, p = 0.001) and nocturnal cough (OR 1.26, CI 1.13-2.43, $\mathrm{p}=0.019)$. Spirometric values were significantly lower than predicted volumes $(p<0.001)$, exhaled nitric oxide levels were raised $(p=0.039)$, nasal cross-sectional areas decreased ( $p=0.005)$, and children complained of rhinoconjunctivitis (OR 3.59, CI 1.49-8.64, $\mathrm{p}=0.003)$. 
Fig. 3. Forest plot showing an association between symptoms and traffic near schools.

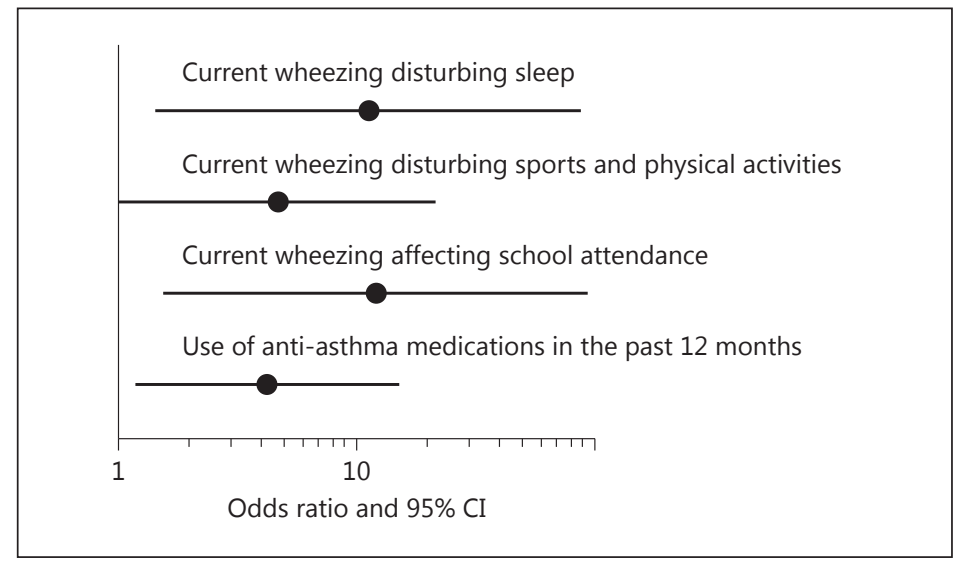

School Building Orientation

Children in classrooms with western and southern window orientations were associated with having rhinoconjunctivitis (OR 4.62, CI 1.33-15.97, $\mathrm{p}=0.009$ and OR 1.17, CI 1.08-1.26, $\mathrm{p}=0.001$, respectively), which resolved on leaving the school environment (OR 4.15, CI 1.19$14.45, \mathrm{p}=0.017)$, with increased eCO ( $\mathrm{p} \leq 0.001)$ levels, decreased nasal cross-sectional areas and volumes ( $\mathrm{p}<0.001)$, and hand/forearm skin rashes (OR 3.34, CI 1.07-10.39, $\mathrm{p}=0.029$ ). Children in those classrooms having openable window areas below the school mean complained of nocturnal dry cough (OR 1.38, CI 1.05-2.66, $\mathrm{p}=0.001$ ) and rhinitic symptoms (OR 3.14, CI 1.2-8.21, $p=0.016)$. These pupils had reduced nasal volumes $(p=0.037)$ and raised eCO $(p=0.035)$ and nasal lavage MPO $(p=0.046)$ levels.

School Maintenance and Environment

Low humidity resulted in less rhinitis (OR $0.21, \mathrm{CI} 0.07-0.62, \mathrm{p}=0.007$ ), while increased humidity was associated with increased eCO $(\mathrm{p}=0.015)$ and nasal lavage MPO $(\mathrm{p}<0.001)$ levels. Itchy rashes (OR 3.36, CI 1.18-9.53, p = 0.025) and eczema (OR 2.34, CI 1.06-5.13, p = 0.032 ) were associated with mould damage in schools.

Closing windows during cleaning resulted in increased phlegm (OR 4.83, CI 1.62-14.42, $p=0.002)$, diminished peak expiratory flow rate $(p=0.048)$ and increased eCO $(p=0.015)$ levels.

Daily floor sweeping routines were associated with current wheezing (OR 4.44, CI 1.49$13.19, \mathrm{p}=0.003)$ and worsening $\mathrm{FEV}_{1}(\mathrm{p}<0.001)$, increased eCO $(\mathrm{p}<0.001)$ and nasal lavage ECP ( $p=0.006)$ levels. In classrooms where flat surfaces were never cleaned, an increase in current wheezing was observed in students (OR 5.89, CI 1.82-19.08, p =0.001), as well as raised exhaled nitric oxide $(\mathrm{p}=0.039)$ levels and current rhinoconjunctivitis (OR 5.08, CI $1.32-19.49, \mathrm{p}=0.003$ ).

\section{Discussion}

This study has shown an increase in the prevalence of cumulative (32.98\%) and current wheezing (17.8\%) and diagnosed asthma (16.75\%) among the study population when compared to the ISAAC data despite the difference in sample size and age [1,23]. Children attending schools located in the southern region of the Maltese islands had the highest prevalence of cumulative and current wheezing. These data are in keeping with the geographical distribution of wheezing in the Maltese islands based on ISAAC phases 1 and 3 [2]. 
ISAAC Malta data have shown that $28.8 \%$ of Maltese children had current rhinitis in 2001 (23.4\% in 1994) [1]. This increasing trend has been confirmed in this study, where $29.84 \%$ of the children complained of rhinitis symptoms during the previous 12 months. The burden of upper airway disease in Maltese school children is evidenced by the fact that the mean total minimal cross-sectional area of the children participating in this study was lower $\left(0.38 \mathrm{~cm}^{2}\right.$, SD 0.25) than published age-matched reference values $\left(0.75 \mathrm{~cm}^{2}\right)$ [24].

The mean nasal volume $\left(4.4 \mathrm{~cm}^{3}\right)$ was similar to age-matched nasal volumes $\left(4.41 \mathrm{~cm}^{3}\right.$, SD 3.55) despite diminished nasal areas. One possible explanation is that airway size alters air volume when nasal cross-sectional area is less than a threshold area of $0.4 \mathrm{~cm}^{2}$ [25].

Tobacco exposure at home was found to be an independent risk factor for exerciseinduced wheezing, itchy rashes and rhinoconjunctivitis. The significant association between cotinine and 3HC and the presence of smokers within the domestic environment shows that future studies should take into consideration ETS exposure as a potential confounding factor.

\section{Interpretation of School versus Health Analysis}

The present study has shown that an association exists between the school environment and the respiratory health of the pupils.

\section{School Location}

The southern regions of the Maltese islands are highly urbanized, and a variety of industries are present. There are several main thoroughfares through which large amounts of traffic pass on a daily basis. Children attending schools in this location were more likely to complain of wheezing and rhinoconjunctivitis and had the highest levels of nasal ECP, indicating increased activity of eosinophil granulocytes. These destroy the upper airway epithelial mucosa acting as a surrogate marker for the impact of airborne pollutants on nasal mucosa [26]. One can speculate that environmental irritants had a negative impact on the nasal mucosa. Exposure to endotoxins in a rural environment during childhood has been found to protect the children from asthma, which could explain the lower prevalence of atopy in our rural schools [27].

Car parks near schools were significantly associated with asthma and the use of medications. Poor school air quality secondary to stationary idling vehicles both on roads and in car parks is frequently overlooked. Ryan et al. [28] have described the beneficial impact of vehicle idling measures around schools on PM2.5 and particle number concentration levels.

Malta has a large oil-fired power plant located in the south of the island. These regions were characterized by an increase in wheezing among children in the ISAAC, and this study confirms that the presence of these installations together with fuel-dispensing facilities near schools have a negative impact on the children's respiratory health [2].

\section{School Building Orientation}

Southern class window orientations were associated with nasal and skin allergies and raised eCO levels. Subclinical airway inflammation manifesting as rhinitis or atopic eczema secondary to an environmental irritant within these classes cannot be excluded [29]. The second most common wind directions in the Maltese islands are west-southwest winds $(8.9 \%)$ and south-southwest winds (7.8\%) [30]. These are characterized by high levels of humidity and dust arising from North Africa, especially the Sahara desert. One can speculate that these winds push outdoor environmental irritants into the classroom, thus accounting for the increased prevalence of allergies in classrooms having southern window orientations. Another potential source of airborne pollutants entering these classrooms is an oil-fired power plant, which is located at the southern end of the Maltese islands. 
School Cleaning and Maintenance

Chew et al. [31] described an association between the presence of cockroach allergen in schools and an increase in asthma symptoms as shown in this study, where eradication of cockroaches actually resulted in an improvement in symptoms and lung function. Daily sweeping of floors resulted in impaired spirometry and raised nasal ECP levels, possibly due to an increase in airborne irritants which would have previously settled over time. Cleaning activities are a source of particulate matter (PM2.5), and increased sensitization to house dust mite and increased levels of serum ECP have been described in subjects who vacuum indoor floors [32].

When flat surfaces were never cleaned, children complained of wheezing and upper airway symptoms. Nasal ECP was higher in these classes, thus highlighting the role of dust allergens within the indoor environment. No high-efficiency particulate air vacuum cleaners are utilized in Maltese schools.

Humidity in our study was associated with atopy, suggesting a possible link between environments favoring mould growth and atopic airway disease. Interestingly, atopic eczema was more likely in classrooms with visible mould damage. Fungal proteases may activate epithelial cells through a protease-activated receptor type 2-driven mechanism [33]. Children in schools having regular pest eradication programs were less likely to complain of atopy.

\section{Conclusion}

This study has shown that there is a high prevalence of atopy among Maltese school children when compared to international data. Children attending schools located in urban areas with high volumes of traffic and industrial activities had a higher prevalence of wheezing and rhinitis when compared to other schools. This study highlights the impact of school indoor and outdoor environment on the students' respiratory health and provides much needed data for the design of an 'ideal' school within the subtropical geographical scenario. Future schools should be located far away from any industrial activities and heavy traffic. Traffic around the school should be kept to a minimum with no car parking facilities situated next to the school building.

Schools should ideally avoid having classrooms with southern-facing windows and have regular pest eradication programs together with standardized cleaning protocols utilizing high-efficiency particulate air filter-equipped vacuum cleaners to regularly remove dust from flat surfaces in classrooms. Parents need to be educated about the problems associated with ETS exposure. More research is needed to identify potential environmental pollutants in schools responsible for the distribution of allergic disease.

\section{Strengths and Limitations}

An even distribution of males and females eliminated gender bias. Due to the small size of the country, there were no confounding microclimates, and the children resided in the town where the school was located.

The main limitation is the relatively small number of children participating when compared to studies such as the ISAAC.

\section{Acknowledgments}

The study was done as part of the European Union SINPHONIE Study commissioned by DG SANCO. The authors received some funding from SINPHONIE (European Commission service contract of the DG Sanco). 


\section{Disclosure Statement}

The authors declare that there were no conflicts of interest within this study.

\section{References}

1 Montefort S, Ellul P, Montefort M, Caruana S, Agius Muscat H: Increasing prevalence of asthma, allergic rhinitis but not eczema in 5- to 8-yr-old Maltese children (ISAAC). Pediatr Allergy Immunol 2009;20:67-71.

2 Fsadni P, Ellul P, Montefort M, Caruana S, Agius Muscat H, Montefort S: ISAAC Malta: changes in geographical distribution of wheezing children in Malta between 1994 and 2002. J Asthma Allergy Educ 2012;3:208-214.

3 Brandenburg AH, Jeannet PY, Steensel-Moll HA, Ott A, Rothbarth PH, Wunderli W, et al: Local variability in respiratory syncytial virus disease severity. Arch Dis Child 1997;77:410-414.

4 Stacey B: Dust Deposition Monitoring in Malta, December 1999 to July 2000, ed 1 ed. Malta, Ministry for the Environment, 2001.

5 NationMaster: Transportation Statistics. Woolwich, NationMaster, 2003-2015. http://www.nationmaster. com/country/mt-malta/tra-transportation (accessed February 2, 2015).

6 Holgate ST, Sandström T, Frew AJ: Health effects of acute exposure to air pollution. Part I: healthy and asthmatic subjects exposed to diesel exhaust. Res Rep Health Eff Inst 2003;112:1-30.

7 Smedje G, Norbäck D: Incidence of asthma diagnosis and self-reported allergy in relation to the school environment - a four-year follow-up study in schoolchildren. Int J Tuberc Lung Dis 2001;5:1059-1066.

8 Grech V, Balzan M, Asciak RP, Buhagiar A: Seasonal variations in hospital admissions for asthma in Malta. J Asthma 2002;39:263-268.

9 Perzanowski MS, Rönmark E, Nold B, Lundbäck B, Platts-Mills TA: Relevance of allergens from cats and dogs to asthma in the northernmost province of Sweden: schools as a major site of exposure. J Allergy Clin Immunol 1999;103:1018-1024.

10 Allermann L, Meyer HW, Poulsen OM, Nielsen JB, Gyntelberg F: Inflammatory potential of dust from schools and building related symptoms. Occup Environ Med 2003;60:E5.

11 Nitschke M, Pilotto LS, Attewell RG Smith BJ, Pisaniello D, Martin J, et al: A cohort study of indoor nitrogen dioxide and house dust mite exposure in asthmatic children. J Occup Environ Med 2006;48:462-469.

12 Lönnkvist K, Halldén G, Dahlén SE, Enander I, van Hage-Hamsten M, Kumlin M, et al: Markers of inflammation and bronchial reactivity in children with asthma, exposed to animal dander in school dust. Pediatr Allergy Immunol 1999;10:45-42.

13 Asher MI, Keil U, Anderson HR: International study of asthma and allergies in childhood (ISAAC): rationale and methods. Eur Respir J 1995;8:483-491.

14 Youth and School Health: EPA's Assessment Tool on the Environment, Healthy SEAT. Washington, Youth and School Health, 2012. https://www.sophe.org/PublicHealth/assessment.cfm (accessed February 2, 2015).

15 Miller R, Crapo R, Hankinson J, Brusasco V, Burgos F, Casaburi R, et al: General considerations for lung function testing. Eur Respir J 2005;26:153-161.

16 Dweik RA, Boggs PB, Erzurum SC, Irvin CG, Leigh MW, Lundberg JO, et al: An official ATS clinical practice guideline: interpretation of exhaled nitric oxide levels (FeNO) for clinical applications. Am J Respir Crit Care Med 2011;184:602-615.

17 Jarvis M, Belcher M, Vesey C, Hutchison D: Low cost carbon monoxide monitors in smoking assessment. Thorax 1986;41:886-887.

18 Hilberg 0, Pedersen OF: Acoustic rhinometry: recommendations for technical specifications and standard operating procedures. Rhinol Suppl 2000;16:3-17.

19 Schmekel B, Karlsson SE, Linden K, Sundström C, Tegner H, Venge P: Myeloperoxidase in human lung lavage I. A marker of local neutrophil activity. Inflammation 1990;14:447-454.

20 Peterson CGB, Nystrand J, Andersson AS, Nilsson L, Venge P: Radioimmunoassay of human eosinophil cationic protein by an improved method. Establishment of normal levels in serum turnoverin vivo. Clin Exp Allergy 1991;21:561-567.

21 Venge P, Hällgren R, Stålenheim G, Olsson I: Effects of serum and cations on the selective release of granular proteins from human neutrophils during phagocytosis. Scand J Haematol 1979;22:317-326.

22 Wålinder R, Norbäck D, Wieslander G, Smedje G, Erwall C, Venge P: Nasal patency and biomarkers in nasal lavage - the significance of air exchange rate and type of ventilation in schools. Int Arch Occup Environ Health 1998;71:479-486.

23 Pearce N: ISAAC - Background and methods. Eur Respir J 1996;9:410.

24 Haavisto LE, Vahlberg TJ, Sipila JI: Reference values for acoustic rhinometry in children at baseline and after decongestion. Rhinology 2011;49:243-247.

25 Hinton VA1, Warren DW, Hairfield WM, Seaton D: The relationship between nasal cross-sectional area and nasal air volume in normal and nasally impaired adults. Am J Orthod Dentofacial Orthop 1987;92:294-298.

26 Norbäck D, Wålinder R, Wieslander G, Smedje G, Erwall C, Venge P: Indoor air pollutants in schools: nasal patency and biomarkers in nasal lavage. Allergy 2000;55:163-170. 
27 Lawson J, Dosman J, Rennie D, Beach J, Newman S, Crowe T, et al: Endotoxin as a determinant of asthma and wheeze among rural dwelling children and adolescents: a case-control study. BMC Pulm Med 2012;12:56.

28 Ryan PH, Reponen T, Simmons M, Yermakov M, Sharkey K, Garland-Porter D, et al: The impact of an anti-idling campaign on outdoor air quality at four urban schools. Environ Sci Process Impacts 2013;15:2030-2037.

29 Pecova R, Frlickova Z, Pec J, Tatar M: Cough sensitivity in atopic dermatitis. Pulm Pharmacol Ther 2003;16: 203-206.

30 Galdies C: The Climate of Malta: Statistics, Trends and Analysis, 1951-2010, ed 8. Valletta, National Statistics Office, 2011.

31 Chew GL, Correa JC, Perzanowski MS: Mouse and cockroach allergens in the dust and air in northeastern United States inner-city public high schools. Indoor Air 2005;15:228-234.

32 Koh GC, Shek LP, Kee J, Tai BC, Wee A, Ng V, et al: An association between floor vacuuming and dust-mite and serum eosinophil cationic protein in young asthmatics. Indoor Air 2009;19:468-473.

33 Kauffman HF, Tomee JF, van de Riet MA, Timmerman AJ, Borger P: Protease dependent activation of epithelial cells by fungal allergens leads to morphologic changes and cytokine production. J Allergy Clin Immunol 2000; 105:1185-1193. 